\title{
PREPARATION AND PROPERTIES OF STARCH-BASED BIOPOLYMERS MODIFIED WITH DIFUNCTIONAL ISOCYANATES
}

\author{
Ramzi Belhassen, ${ }^{\mathrm{a}}$ Fabiola Vilaseca, ${ }^{\mathrm{b}}$ Pere Mutjé, ${ }^{\mathrm{b}}$ and Sami Boufi ${ }^{\mathrm{a}, *}$ \\ The present work reports on the preparation of thermoplastic starch \\ (TPS) modified in situ with a diisocyanate derivative. Evidence of the \\ condensation reaction between the hydroxyl groups of starch and \\ glycerol with the isocyanate function (NCO) was confirmed by FTIR \\ analysis. The evolution of the properties of the ensuing TPS, in term of \\ mechanical properties, microstructure, and water sensitivity, was \\ investigated using tensile mechanical, dynamic mechanical thermal \\ analysis (DMTA), X-ray diffraction (XRD), and water uptake. The results \\ showed that the addition of isocyanate did not affect the crystallinity of \\ the TPS and slightly reduced the water uptake of the material. The \\ evolution of the mechanical properties with ageing became less \\ pronounced by the addition of the isocyanate as their amount exceeded \\ 4 to $6 w t \%$.
}

Keywords: Starch; Isocyanate; Thermoplasticized starch; Microstructure; Water uptake; Mechanical properties

Contact information: a: Laboratoire Sciences des Matériaux et Environnement (LMSE), Faculte des Sciences de Sfax, University of Sfax, BP 802-3018 Sfax, Tunisia; $b$ : LEPAMAP group, University of Girona, Campus Montilivi, 17071, Girona, Spain *Corresponding author: sami.boufi@fss.rnu.tn; pere.mutje@udg.edu

\section{INTRODUCTION}

As is well known, synthetic polymer materials have been widely used in every field of human activity during recent decades. These artificial macromolecular substances usually originate from petroleum, and most of the conventional ones are regarded as nonbiodegradable. However, petroleum resources are limited, and the expanding use of nonbiodegradable polymers has caused serious environmental problems (Lu et al. 2009).

Starch is a natural polymer regenerated from carbon dioxide and water by photosynthesis in plants (Teramoto et al 2003). Owing to its complete biodegradability (Araújo et al. 2004), low cost, and renewability (Silva et al. 2008), starch is considered to be a good candidate for developing sustainable materials. In view of this, starch has been receiving growing attention since the 1970s (Griffin 1994; Pareta and Edirisinghe 2006). Many efforts have been exerted to develop starch-based polymers for conserving petrochemical resources, reducing environmental impact, and searching for more applications (Park et al. 2004; Schwach and Avérous 2004).

For this reason, polymers based on starch are seen as an attractive alternative to polymers issued from petrochemicals and are considered as one of the most important groups of commercially available and sustainable bio-based polymers with a relatively low cost. The worldwide production capacity for bio-based polymers is growing 
continuously and is emerging from being a niche market to move to a mass production scale.

Given the high glass transition temperature of pure starch, being above its decomposition temperature, and to its partially crystalline structure ranging from 15 up to $45 \%$ (VanSoest et al. 1995), the processing of starch using conventional plastic processsing techniques cannot be carried on without incorporation of plasticizing agents such as glycerol, polyethers, or with the addition of a thermoplastic material with greatly enhanced processability compared to granular starch (Gomez and Aguilera 1984; Shogren et al. 1993; Wiedmann and Strobel 1991; da Róz et al 2006; Belgacem and Gandini 2008; VanSoest et al. 1996). Under the combined effect of heating and shearing, the plasticizer diffuses inside the granules and disrupts the inter-macromolecule hydrogen links among amylose and amylopectin, giving rise to gelatinisation and melting below the decomposition temperature. Unfortunately, the high sensitivity of TPS to humidity and its tendency to undergo retrogradation (Smits et al. 2003) after being stored for a period of time, lead to a strong evolution of mechanical properties such as the tensile modulus, tensile strength, and the deformation at break (Forssell et al. 1999).

One strategy that has been widely adopted to fulfill various industrial applications consists in the association of TPS with another polymer in the form of a blend or multilayer product (Avérous et al. 1999) which may take place either during or after extrusion. Thus, it is usual to find literature accounts of blended TPS with other biodegradable polymers (Avérous 2004; Wang et al. 2003; Amass et al. 1998) such as polycaprolactone (PCL), polylactic acid (PLA), polyhydroxybutyrate-covalerate (PHBV), or polyesteramide. Partial modification of starch with functional reactive additive such as anhydride, oxypropylene (Lafarge et al. 2007; de Menezes et al. 2007), or isocyanate derivative may be another alternative to improve the material properties and to overcome the inherent shortcoming.

Only few works have been reported regarding the modification of starch or plasticized starch with isocyanate reagent. Carvalho et al. (2005) treated thermoplastic starch (TPS) films plasticized with glycerol using several reagents bearing phenolblocked isocyanates in order to make their surface less sensitive to moisture. However, the modification was limited to the surface, and the effect of such treatment on the mechanical properties was not investigated. Wilpiszewska and Spychaj (2007) prepared starch-urethane polymers via chemical modification of potato starch with urethane and urea derivatives of hexamethylene diisocyanate. They showed that starch polymers with a substitution degree in the range of 1.6-1.8 exhibit acceptable bulk hydrophobic properties and melt flow features in hot press test. However, the chemical modification of potato starch was carried out in a two-step process, being a less viable method. Wu et al., (2008) studied the formation of TPS/PU materials via intensive mixing/gelatinization of starch with water and next with MDI-based urethane oligomer, ended up with isocyanate groups; such materials were processed by compression molding. Recently, da Róz et al. (2009) reported the preparation and characterization of starch cross-linked polyurethanes produced by the reaction of cornstarch with a propylene oxide toluene diisocyanate oligomer in DMSO solution. The ensuing materials were totally amorphous and displayed elastomeric properties with reduced hydrophilicity. 
The aim of this work was to study the effect of the incorporation of isocyanate additive on the mechanical behaviour and water absorption properties of glycerol plasticized starch.

\section{EXPERIMENTAL}

\section{Materials}

Native cornstarch, provided by Roquette Laisa España, S.A. (Barcelona, Spain), was used as polymer base material. This material is a non-modified starch typically used as an additive in the paper industry. Glycerol (Gly) provided by Quimivita, S.A. (Sant Adrià de Besós, Spain) was used as plasticizer without prior purification. Methylenebis(phenylisocyanate) (MDI), hexamethylendisocyanate (HDI), tolylenendiisocyanate (TDI), and dibutyltindilaurate (DBTL) were supplied by Sigma Aldrich (Madrid, Spain).

\section{Methods}

Polymer matrix plasticizing

A pre-blending process of native starch, water, and glycerol was carried out in a low density polyethylene bag. The components were mixed for $45 \mathrm{~min}$ by hand until a homogeneous high viscosity mass was obtained. Afterwards, the pre-blend was added in an internal mixer (Brabender Plastograph ${ }^{\mathrm{TM}}$, Duisburg, Germany) working at 120, 130, or $140{ }^{\circ} \mathrm{C}$, and $80 \mathrm{rpm}$. Subsequently, and after complete water evaporation, the diisocyanate was added. In the case of TDI and HDI, the feeding system of the Brabender mixer was kept thoroughly closed to avoid any risk of isocyanate leak by volatilization. The Brabender mixing was carried out under a powerful extraction system to avoid health risks (TDI is volatile and highly toxic product). The obtained materials were labeled according to the following nomenclature: $\mathrm{ST}_{\mathrm{xx}} \mathrm{GLY}_{\mathrm{yy}} \mathrm{W}_{\mathrm{zz}} \mathrm{DI}_{\mathrm{ww}}$, where ST, GLY, W, and DI refer to starch, glycerol, water, and di-isocyanate, respectively, and the subscripted numbers indicate the $\mathrm{wt} \%$ of each component with respect to the final weight. The absence of one acronym in the name reflects the absence of this component in the final formulation.

\section{Compression Molding Processing}

Each formulation was pelletized in order to obtain a particle size able to be processed by compression moulding. Therefore, the materials were ground using a mill (Agrimsa $^{\mathrm{TM}}$, Sant Adrià del Besos, Spain) equipped with a set of knifes and sieves. Once pelletized, the material was introduced in a stainless mould for obtaining specimens according to ASTM D638 standard specifications, and placed in a laboratory hot-press LabEcon300 (Fontijne Grotnes ${ }^{\mathrm{TM}}$, Vlaardingen, The Netherlands). The procedure of the compression moulding is summarised in Table 1. During the first stage of the compression moulding, the material was melted by approaching the warm plates of the press to soften the material prior compression. 
Table 1. Temperature and Closing Pressure Sequence Applied for Compression Moulding of Thermoplastic Starch

\begin{tabular}{|c|c|c|}
\hline $\begin{array}{c}\text { Time } \\
(\mathbf{m i n})\end{array}$ & $\begin{array}{c}\text { Temperature } \\
\left(\mathbf{(}^{\circ} \mathbf{C}\right)\end{array}$ & $\begin{array}{c}\text { Closing pressure } \\
\left(\mathbf{k g f} \cdot \mathbf{c m}^{-2} \mathbf{)}\right.\end{array}$ \\
\hline 0 & $180^{\circ} \mathrm{C}$ & 0 \\
\hline 8 & $180^{\circ} \mathrm{C}$ & 6 \\
\hline 13 & $180^{\circ} \mathrm{C}$ & 30 \\
\hline 21 & Cooling until 55 ${ }^{\circ} \mathrm{C}$ & 30 \\
\hline 26 & Acquisition of specimens at \\
$55^{\circ} \mathrm{C}$ & 0 \\
\hline
\end{tabular}

\section{Fourier Transform Infrared Spectroscopy (FTIR)}

The reaction between isocyanate and TPS was monitored with a FTIR Perkin Elmer instrument model BXII equipped with a temperature-controlled sample holder that allowed the in situ analysis of the condensation reaction between isocyanate and TPS. Each sample in the form of a thin film with thickness less than $100 \mu \mathrm{m}$ was prepared by pressing the TPS blend containing $20 \%$ water between a Teflon sheet at $100^{\circ} \mathrm{C}$, then the film was introduced in the measuring cell purged with dry nitrogen and kept at $90^{\circ} \mathrm{C}$ for 5 min until the peak at $1645 \mathrm{~cm}^{-1}$ associated with water completely vanished. Then, the film was coated with the appropriate amount of isocyanate dissolved in methylenechloride and pressed in a sandwich again to ensure homogenous distribution within the TPS film, and the FTIR spectrum was recorded at regular intervals by means of 4 scans with a resolution of $4 \mathrm{~cm}^{-1}$. The vibration band of the NCO chemical group, which appears at 2270 to $2250 \mathrm{~cm}^{-1}$, has been chosen to monitor the isocyanate reaction. The degree of NCO conversion has been calculated from the peak areas according to Eq. 1,

$$
\% N C O=\frac{A_{0}-A}{A_{0}}
$$

where $A_{0}$ and $A$ denote the absorbance of the NCO band at $2260 \mathrm{~cm}^{-1}$, at the initial time and at an instant $t$, as determined from in situ FTIR spectra.

\section{Water Uptake}

Different fractions of specimens of each material obtained after compression moulding were submitted to a controlled environment of $23{ }^{\circ} \mathrm{C}$ and $50 \%$ relative humidity by using a climate chamber from Dycometal (Sant Boi del Llobregat, Spain). Each material was assayed in triplicate. The water uptake was evaluated by weighting the samples after different periods of time. The water uptake was determined according to Eq. 2, 


$$
W . U .=\frac{\left(W_{2}-W_{1}\right)}{\left(W_{1}\right)} \times 100
$$

where $W_{1}$ is the initial weight of the sample before conditioning and $W_{2}$ is that obtained after the corresponding period of time.

\section{Mechanical Properties}

Tensile test was carried out by means of a Universal testing machine (Instron 1122, Zamudio, Spain) equipped with $5 \mathrm{kN}$ load and according to ASTM D638 standard specifications. The specimens were assayed after $48 \mathrm{~h}$ of conditioning at $23^{\circ} \mathrm{C}$ and 50 $\mathrm{wt} \%$ of moisture. Another set of specimens was tested after reaching the water content equilibrium $\left(\mathrm{M}_{\infty}\right)$.

\section{Dynamic Mechanical Thermoanalysis}

Dynamic mechanical analysis was conducted in a tension mode using a Diamond DMA7 (Perkin-Elmer). Temperature scans were run from -80 to $100^{\circ} \mathrm{C}$ at a heating rate of $2{ }^{\circ} \mathrm{C} / \mathrm{min}$, a frequency of $1 \mathrm{~Hz}$, and an amplitude deformation of $10 \mu \mathrm{m}$. The storage $\left(E^{\prime}\right)$ and the loss $\left(E^{\prime \prime}\right)$ modulus of the sample and the loss factor $\tan \delta\left(E^{\prime \prime} / E^{\prime}\right)$ were measured as a function of temperature. Sample dimensions were about $20 \mathrm{~mm}$ length, 5 $\mathrm{mm}$ width, and $2 \mathrm{~mm}$ thick. The main relaxation temperature $T$ is defined as the temperature where the maximum of $\tan \delta$ is reached.

\section{X-Ray Diffraction Measurement}

Diffractograms were recorded using a Bruker powder diffractometer (Model D8 Advance) operating at the $\mathrm{CuKa}$ wavelength of $1.542 \AA$. Measurements of diffracted intensities were made over the angular range of $7-40^{\circ}(2 \theta)$ at ambient temperature, with an increment step of $0.1^{\circ}$ and a rate of 1 step per $10 \mathrm{~s}$ were used. Unless otherwise specified, all the samples were previously conditioned at $53 \%$ relative humidity for 40 days. The compression-moulded samples were cut and milled during $5 \mathrm{~s}$ in order to obtain a powder. The crystallinity degree was estimated using the area ratio between the crystalline peak and the amorphous area.

\section{RESULTS AND DISCUSSION}

To select the appropriate reaction conditions in terms of the reaction temperature and the residence time of the isocyanates with melted plasticized starch, FTIR analysis was used to monitor the in situ disappearance of the NCO band at 2260-2270 $\mathrm{cm}^{-1}$ during the reaction of isocyanates with TPS. Several precautions were taken in order to simulate the condition during the blending process. In the first step thin films of TPS, with thickness less than $100 \mu \mathrm{m}$, were prepared by pressing the TPS blend containing $20 \%$ water between Teflon sheets at $100^{\circ} \mathrm{C}$, then the film was introduced in the measuring cell and kept at $90^{\circ} \mathrm{C}$ for 5 min until the peak at $1645 \mathrm{~cm}^{-1}$ associated to water completely vanished. Thereafter, the film was coated with isocyanates solution and pressed into a 
sandwich form again to ensure homogenous distribution within TPS film, and the FTIR spectra was recorded at regular intervals.
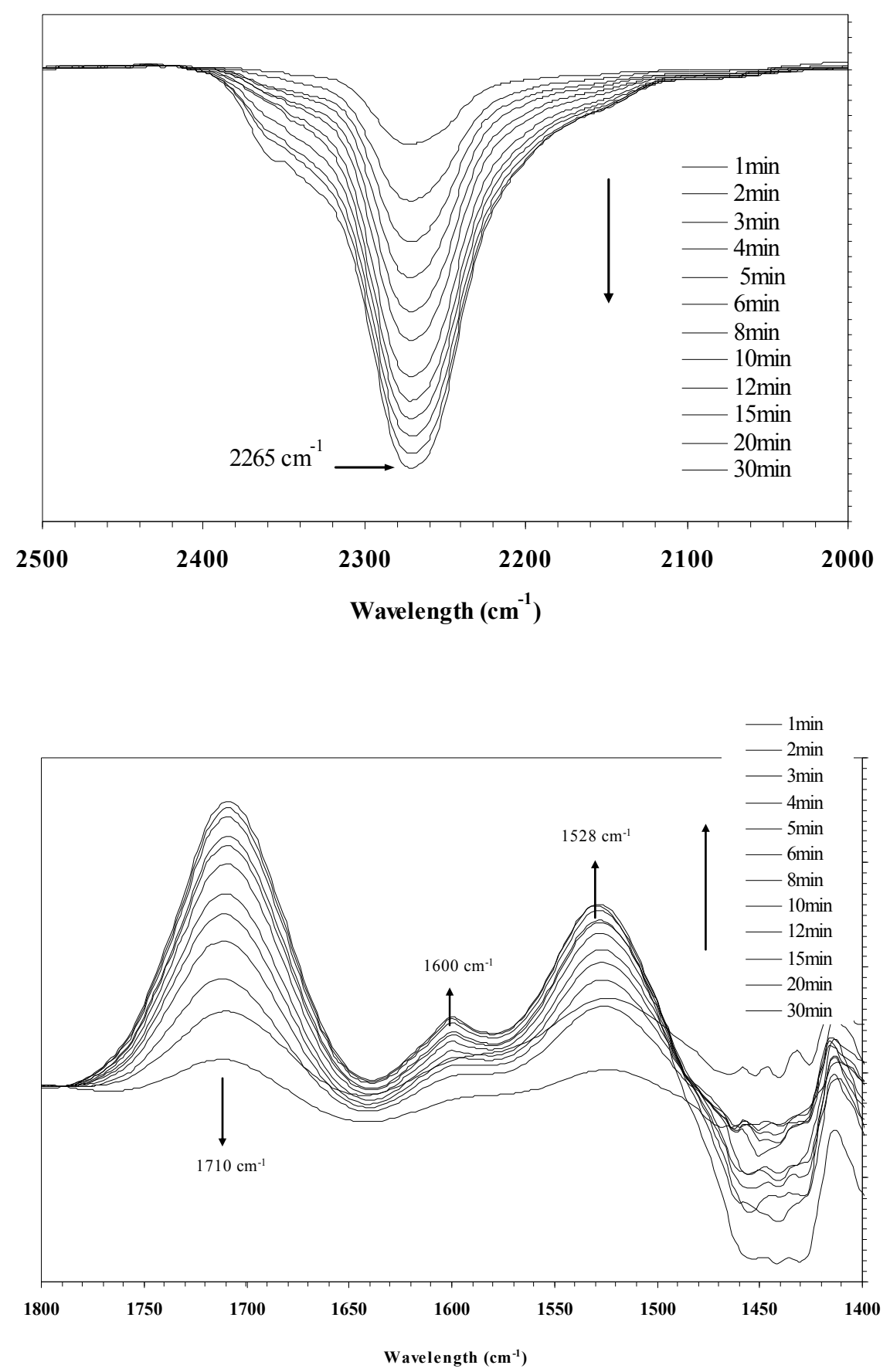

Fig. 1. FTIR spectra of TPS film during reaction with $\mathrm{MDI}$ at $110^{\circ} \mathrm{C}$ recorded in situ at different time after the background recording (two detailed region). Arrows indicate the time evolution 


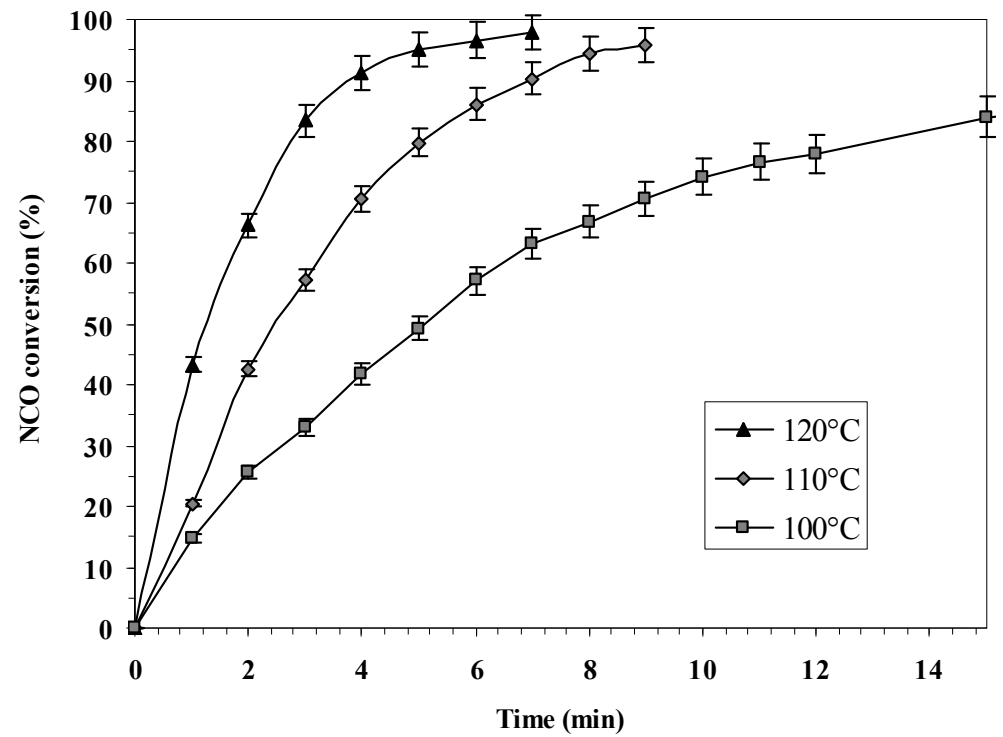

Fig. 2. Evolution of the isocyanate conversion with time during the in situ reaction of MDI with TPS film at different temperature

In order to obtain better evidence for the evolution in the spectra during reaction, the spectral difference between the reference spectrum recorded at $t=0$ and the spectra at time $t$ were plotted.

Table 2. Time Needed for MDI, TDI and HDI to Attain 95\% Isocyanate Conversion with TPS at Different Temperatures

\begin{tabular}{|c|c|c|}
\hline Isocyanate * & $\begin{array}{c}\text { Temperature } \\
\left({ }^{\circ} \mathrm{C}\right)\end{array}$ & $\begin{array}{l}\text { Time to attain } \\
95 \% \text { conversion } \\
\text { (min) }\end{array}$ \\
\hline MDI & $\begin{array}{c}90 \\
100 \\
110 \\
120\end{array}$ & $\begin{array}{c}44 \\
25 \\
8 \\
5\end{array}$ \\
\hline TDI & $\begin{array}{l}100 \\
110 \\
120\end{array}$ & $\begin{array}{c}18 \\
6 \\
4\end{array}$ \\
\hline HDI & $\begin{array}{l}130 \\
140\end{array}$ & $\begin{array}{l}65 \\
43\end{array}$ \\
\hline $\mathrm{HDI}^{\star \star}$ & $\begin{array}{c}90 \\
100 \\
110 \\
120\end{array}$ & $\begin{array}{l}40 \\
30 \\
25 \\
11\end{array}$ \\
\hline $\begin{array}{l}\text { * Isocyanate an } \\
\text { ** In presence o }\end{array}$ & $\begin{array}{l}6 \text { based on } 7 \\
\text { TL. }\end{array}$ & \\
\hline
\end{tabular}


Following this procedure, one can ensure that positive (negative) peaks appearing in the spectra are due to species appearing (vanishing). Examples of spectra corresponding to the interaction of TPS film with MDI isocyanate at $110^{\circ} \mathrm{C}$ are shown in Fig. 1. One can observe the continuous decrease in the intensity of the NCO band at 2265 $\mathrm{cm}^{-1}$, as well as the emergence of new peaks at $1710 \mathrm{~cm}^{-1}$ assigned to the $\mathrm{CO}$ stretching vibration of the ensuing urethane and those at 1528 and $1600 \mathrm{~cm}^{-1}$ attributed to $\mathrm{NH}$ inplane bending modes of the carbamate and $\mathrm{C}=\mathrm{C}$ of the MDI aromatic ring. The decrease in the absorbance of the NCO peak could be correlated with the conversion of the isocyanates vs. time, from which the kinetic of the condensation reaction could be followed. An example of the conversion of NCO function vs. time is shown in Fig. 2, and the time required to attain $95 \%$ conversion for the different isocyanates at 110 and $120^{\circ} \mathrm{C}$ is reported in Table 2.

From these data one can note that aromatic MDI and TDI isocyanates were much more reactive than aliphatic HDI and attained $95 \%$ conversion within 5 min at $120^{\circ} \mathrm{C}$. On the other hand, for HDI it was necessary to add DBTD catalyst in order to ensure high conversion within several min, which is in line with the well-known higher reactivity of aromatic isocyanates (Ortel 1994).

The torque development vs. time at different glycerol (GLY) content (Figs. 3a and $3 \mathrm{~b})$ displayed four steps. Initially, the torque started to increase rapidly $(0.5 \mathrm{~min})$ and attained about 10 to 13 N.m as a result of the melting of granular starch and the onset of mixture gelatinization. Thereafter, the torque increased again to level off, after $6 \mathrm{~min}$, at a stable value at about 15, 20, and $27 \mathrm{Nm}$ for a glycerol content 29, 24, and 19\%, respectively. The higher the amount of GL plasticizer, the lower was the torque at the plateau, which is in line with the plasticizing action of glycerol leading to a decrease of the melt viscosity of TPS.

The rise in the torque was related to the water evaporation during the mixing process $\left(140^{\circ} \mathrm{C}\right)$, which was accomplished explicitly in order to be able to add iscoyanate later without any risk of the hydrolysis of the -NCO group with residual water. It is worth noting that the recovered amount of TPS after mixing corresponded closely to the quantity of the initial starch and glycerol introduced.

It can be seen (Fig. 4b) that the addition of isocyanate did not result in a significant increase in the torque in spite of the difunctional character of isocyanate component. This suggests that isocyanates addition at a level lower than $10 \%$ will not bring about a significant rise in the molecular weight or partial cross-linking of the starch chains, meaning that among the different reaction likely to occur (see Fig. 4), routes 2 and 3 are the more favoured. This hypothesis is reasonably expected due to the much higher proportion of $\mathrm{OH}$ groups (issuing from starch and glycerol) with respect to $\mathrm{NCO}$ function, and the low probability of a terminal NCO groups interacting with adjacent amylose or amylopectin chains. Indeed if we consider $100 \mathrm{~g}$ of the composition $\mathrm{ST}_{57} \mathrm{GL}_{19} \mathrm{~W}_{23}-\mathrm{HDI}_{6}$, then after the water evaporation, the amount of hydroxyl groups from starch and glycerol would be 1.03 and $0.6 \mathrm{~mol}$ respectively, which are much higher values than the $\mathrm{NCO}$ function $(0.067 \mathrm{~mol})$. 


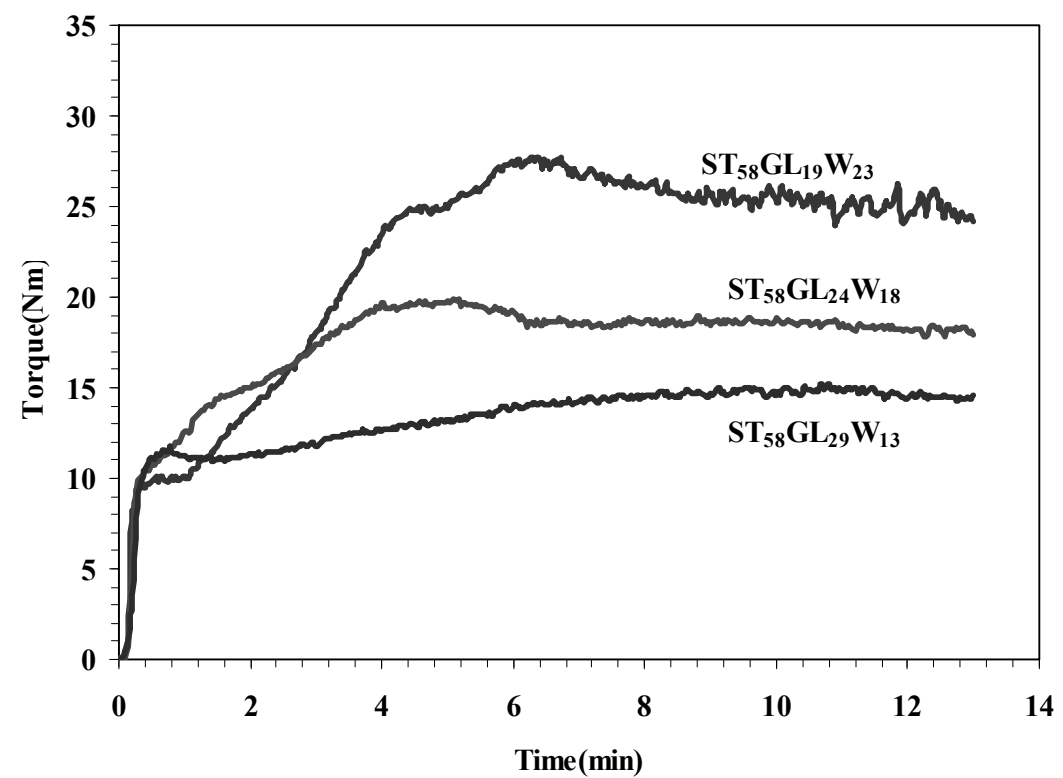

(a)

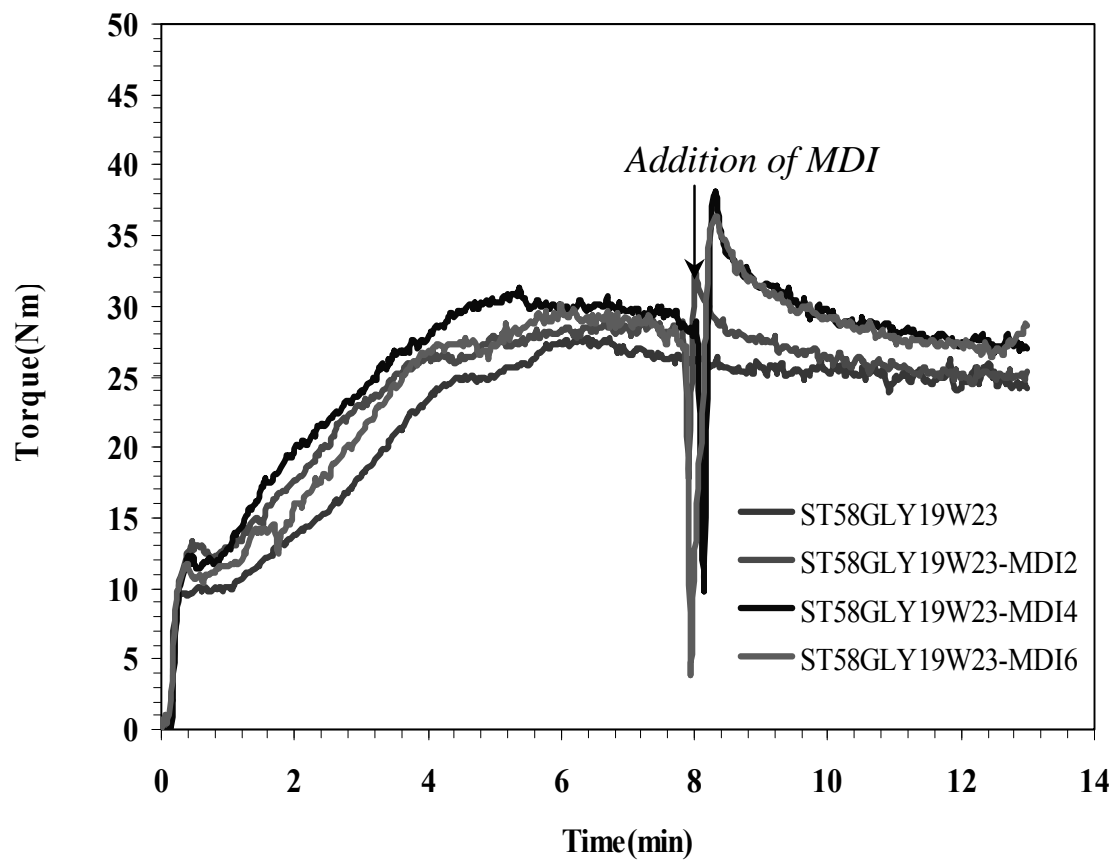

(b)

Fig. 3. Torque profiles in the internal mixing at different glycerol content (a) and at different MDI content for the formulation $\mathrm{ST}_{58} \mathrm{GLY}_{19} \mathrm{~W}_{23}$ (b) 


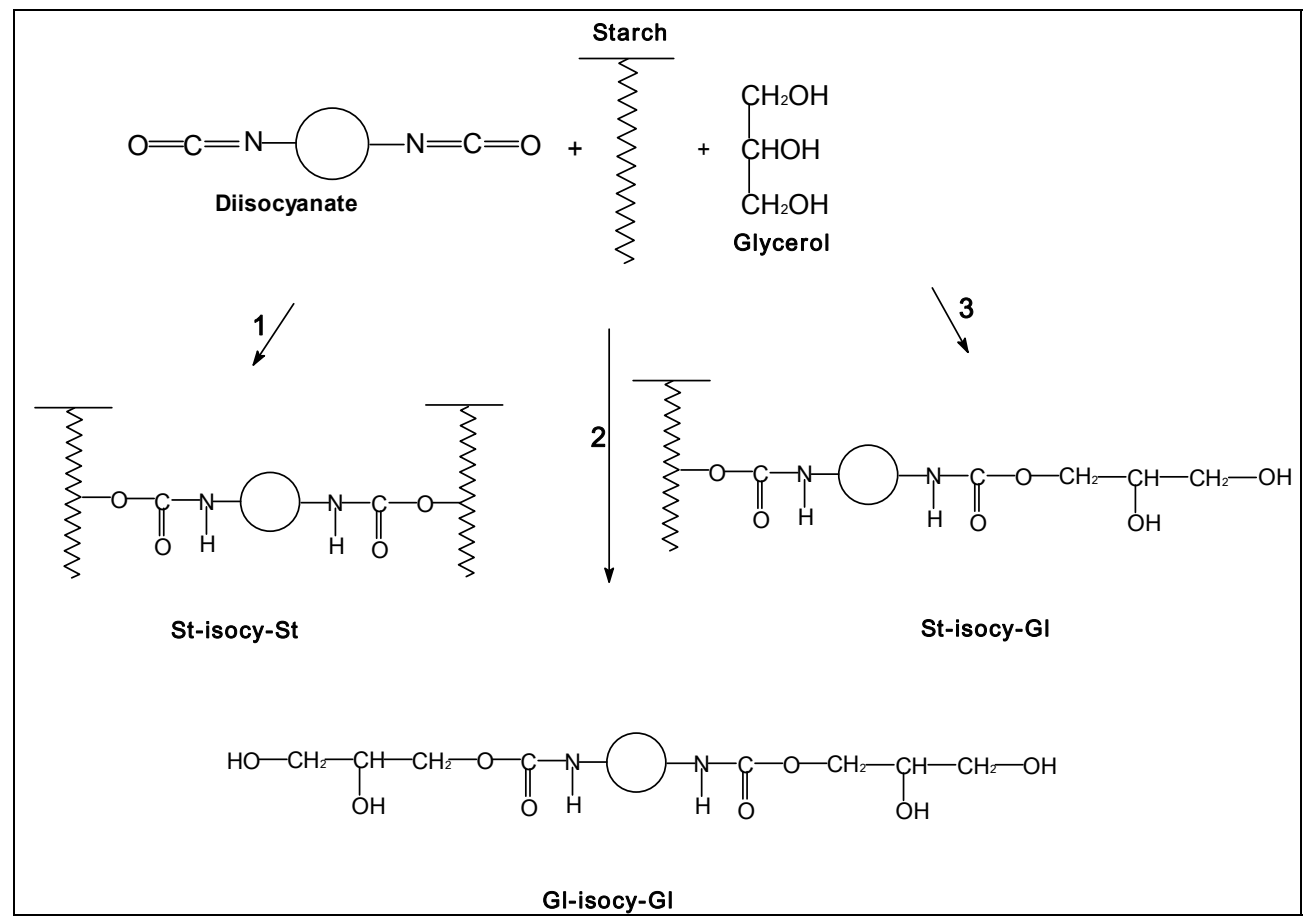

Fig. 4. Different possible reactions likely to occur between starch isocyanate and glycerol during processing

It is worth noting that the isocyanante additive was added after thorough plasticizing had been achieved with the evaporation of the entirety of the added water, as attested by the constant value of the torque. The mixing was maintained for $5 \mathrm{~min}$ at $120^{\circ} \mathrm{C}$ to ensure complete reaction of NCO function with glycerol and starch hydroxyl groups.

The occurrence of the condensation reaction between the terminal isocyanate function and the hydroxyl groups of starch or glycerol during the processing step was confirmed by FTIR (Fig. 5), showing the emergence of new bands in the CO region between 1690 and $1770 \mathrm{~cm}^{-1}$ and at 1510 to $1540 \mathrm{~cm}^{-1}$ in TPS in situ modified by MDI at different amounts between 2 and 10\%. Further, the appearance of bands with different components at $1690,1710,1720$, and $1735 \mathrm{~cm}^{-1}$ confirms that the condensation between the $\mathrm{NCO}$ and the $\mathrm{OH}$ involved different hydroxyl functions with different environments, supporting the assertion that the isocyanate had reacted not only with the anhydroglucosic cycle of starch, but also with glycerol. It should be noted that in order to avoid the interference of the water band at $1640 \mathrm{~cm}^{-1}$ with those of the TPS, the samples were previously dried for $5 \mathrm{~min}$ at $100^{\circ} \mathrm{C}$ to remove the adsorbed water from the material.

\section{Structural Characterization}

The crystallinity degree of TPS is an important parameter that affects the useful properties of the material and considerably affects its mechanical and barrier properties. During processing, plasticizer molecules enter into the starch granules, replacing starch intermolecular and intramolecular hydrogen bonds with starch-plasticizer hydrogen 
bonds and destroying the lattices of crystalline domains. During storage (ageing) of plasticized starch, a time-induced recrystallisation (retrogradation), involving amylose reorganisation in helical structure occurs.

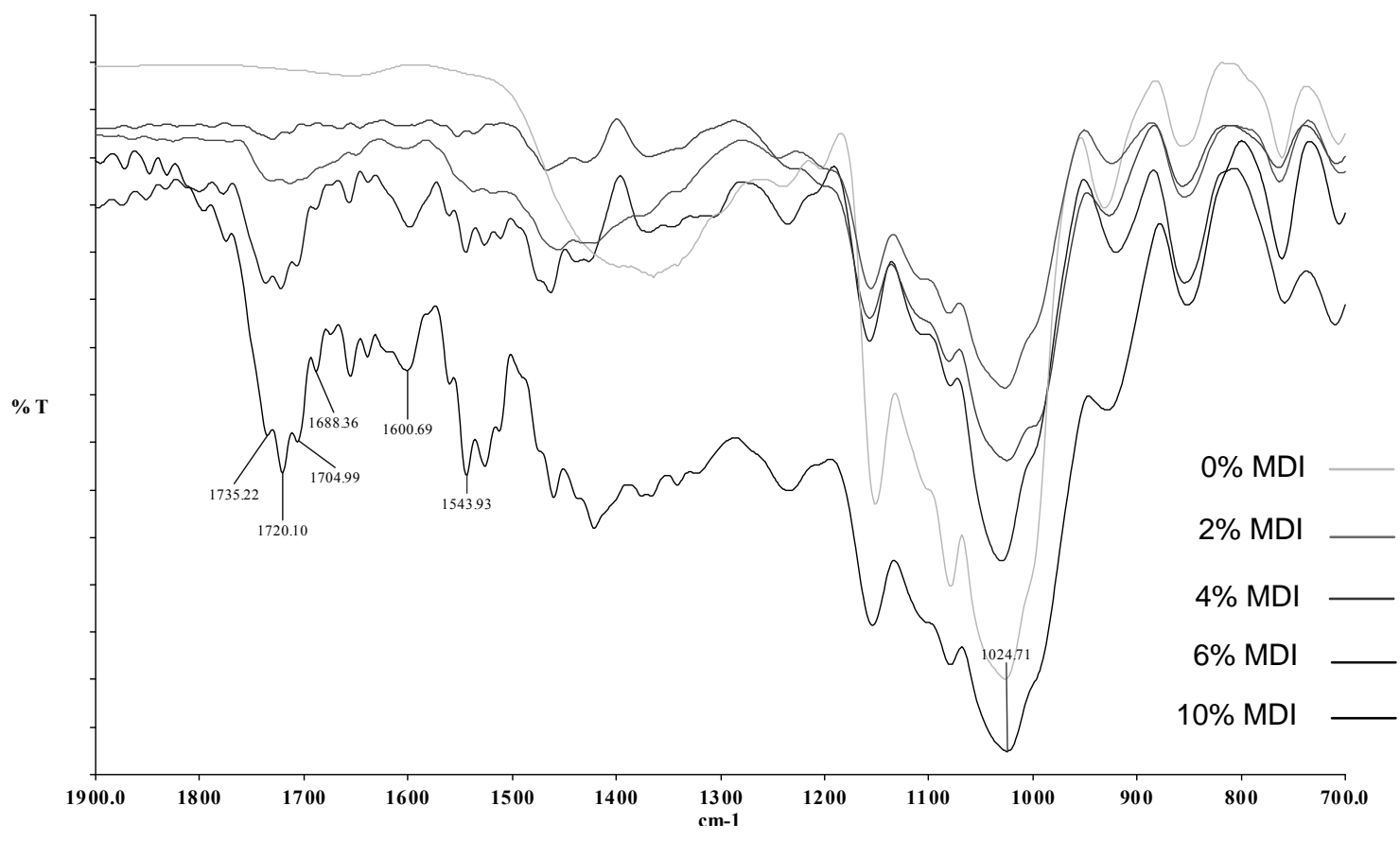

Fig. 5. FTIR spectra (region between 700 to $1900 \mathrm{~cm}^{-1}$ ) corresponding to $\mathrm{ST}_{58} \mathrm{GLY}_{19} \mathrm{~W}_{23}$ modified with different amount of MDI

Unlike native starch, which exhibits A-, B-, or C-type crystal lattices with a double helical structure, the most common crystalline arrangements in plasticized starch are E- and V-type structures, single-helical 'inclusion complex' structures made up of amylose and glycerol (Souza and Andrade 2002). X-ray diffraction has been used for investigating changes in crystallinity during processing and further conditioning. For all the studied compositions, two diffraction peaks at angles (20) of 13.7 and 20.8 were observed, indicating a Va-type crystalline structure. The residual crystalline peaks for the native starch crystals at $\sim 17^{\circ}$ were absent (within the resolution limits), suggesting that the inherent granular, crystalline structure of the native starch was completely disrupted during the processing condition. The evolution of X-ray diffractograms of composition $\mathrm{ST}_{58} \mathrm{GLY}_{19} \mathrm{~W}_{23}$ at different ageing time and at 50\% RH is shown in Fig. 6a, and the data obtained regarding the crystallinity degree of the different composition after ageing for 15 days at $50 \% \mathrm{RH}$ are collected in Table 3. Just after processing, the plasticized starch was highly amorphous, and later the crystallinity increased rapidly during the first hours of storage, attaining its nominal level after $4 \mathrm{~h}$. However, the crystallinity degree was relatively low and did not exceed $10-11 \%$ with a plasticizer content ranging from 19 to $29 \%$. The rise in the plasticizer level from 19 up to $29 \%$ and the addition of isocyanate up to $10 \%$ did not alter the $\mathrm{V}$-type crystallinity nor affect the crystallinity degree, which remained roughly constant within the measurement error. 


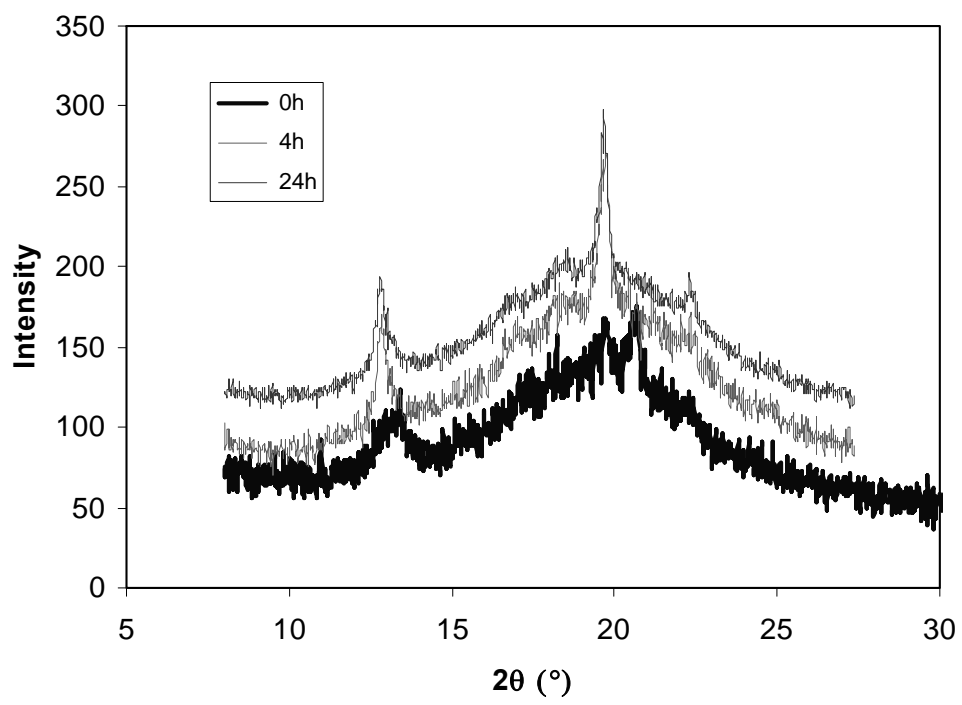

(a)

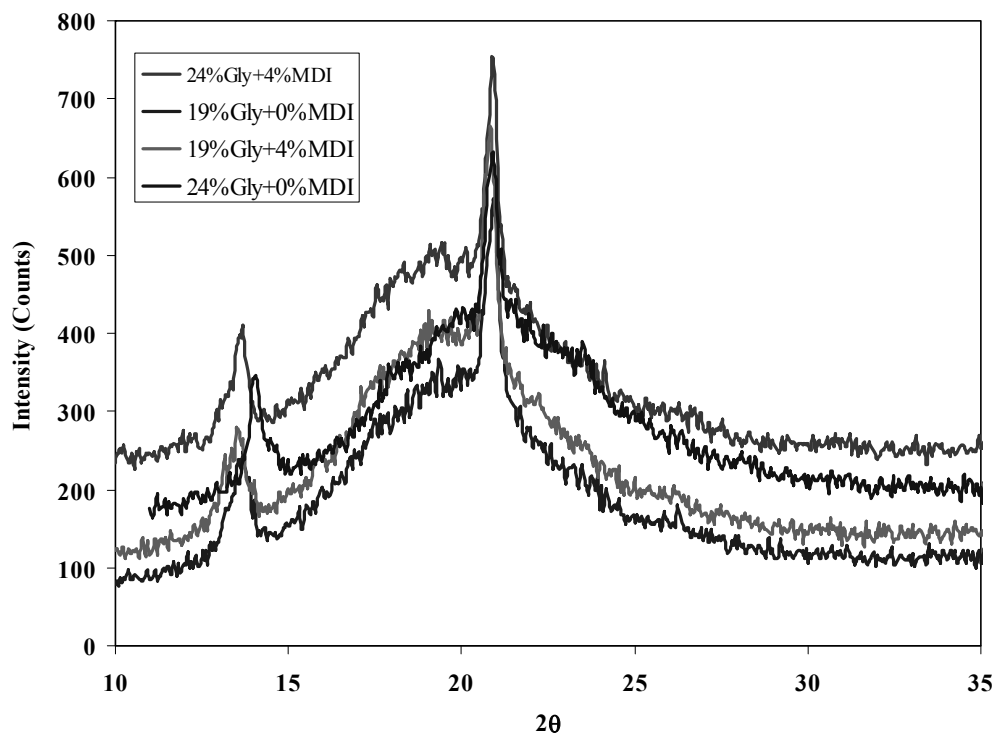

(b)

Fig. 6. X-Ray diffraction patterns of $\mathrm{ST}_{58} \mathrm{GLY}_{19} \mathrm{~W}_{23}$ samples at different storing time under $50 \%$ relative humidity and $23^{\circ} \mathrm{C}(\mathrm{a})$; and X-Ray diffraction patterns of TPS at different glycerol content and without and comprising $4 \%$ of $\mathrm{MDI}(\mathrm{b})$

\section{Tensile Tests}

The Young's modulus (E), tensile strength (TS), and elongation at break $(\varepsilon)$ were determined from stress-strain curves at room temperature after 2 days and 40 days of ageing. Different insights arise from the viewing of Figs. 7, 8, and 9. The obtained results can be summarized as follows: 
(i) The modulus and the tensile strength decreased with increasing of the glycerol level, which is in line with the well known plasticizing effect of glycerol that reduces the degree of interaction between starch chains.

(ii) The modulus and the tensile strength declined after 40 days ageing, while the strain rose significantly, indicating an enhancement of the plasticizing degree of the material. This result disagrees with other reported work (VanSoest and Knooren 1997), which pointed to a rather stiffening effect of the aged TPS that was attributed to the tendency of amylopectin chains to recrystallize (retrogradation) after being stored for a period of time. In fact, two opposite actions account for the evolution of the mechanical properties of TPS: on the one hand the water uptake of the material that contributes to boost plasticizing effect, and on the other hand the crystallisation taking part in the material that acts as a reinforcing element. Given the observed trend, it appears that the effect of water uptake prevailed over the crystallisation action. The low crystallinity degree of the ensuing plasticized starch explains the low contribution of the crystallinity to the mechanical properties of the material.

(iii) The drop in the modulus and in the tensile strength became less pronounced in the presence of TDI and MDI as their amount exceeded 4 and $6 \mathrm{wt} \%$, respectively. In the absence of isocyanate, the fall in the modulus and the strength was about 10 and 2.5 times, respectively, while it did not exceed 3 and 1.25 times in the presence of $6 \mathrm{wt} \%$ MDI or $4 \mathrm{wt} \%$ TDI. Hence the addition of MDI or TDI contributes to stabilize the plasticized starch and reduce the drop in mechanical properties induced by water absorption. This result is the consequence of the isocyanante reaction with a part of starch chains and/or glycerol molecules. However, with HDI, the effect imparted by the addition of isocyanates was insignificant. This effect may result from the relatively long linear aliphatic chain of HDI, with isocyanate the function being separated by 6 methylene groups, contributing to enhance the plasticizing mechanism.

(iv) The strain at break increased significantly after storage. The addition of MDI, TDI or HDI resulted in a continuous drop in the strain at break; the more pronounced is in presence of MDI and TDI. For example, in the absence of isocyanate, the strain at break rose by about 100 times after aging for 40 days, while the rise did not exceed 20 and 10 times in the presence of 4 and $6 \%$ HDI, respectively.

\section{Water Uptake}

The water uptake versus time was also investigated, and the maximum water uptake (MWU) and the data are reported in Table 3. Results indicated that the rise in the glycerol content increased the amount of water absorbed by the TPS at equilibrium and lowered the time needed to attain the absorption equilibrium. The moisture uptake at equilibrium attained 7.6, 8.5, and 9.5\%, and the equilibrium time was about 17, 23, and 30 days for formulations comprising 19, 24, and $29 \%$ of glycerol, respectively. These results are well established and are attributed, on the one hand to the noticeable hydrophilic character of glycerol, enhancing the water interaction with the material at RH exceeding 50\% (Talja et al. 2007; Lourdin et al. 1997), and on the other hand to the decrease in the glass transition of the material allowing greater, easier, and more rapid diffusion of the water inside the material (Gaudin et al. 1999). 


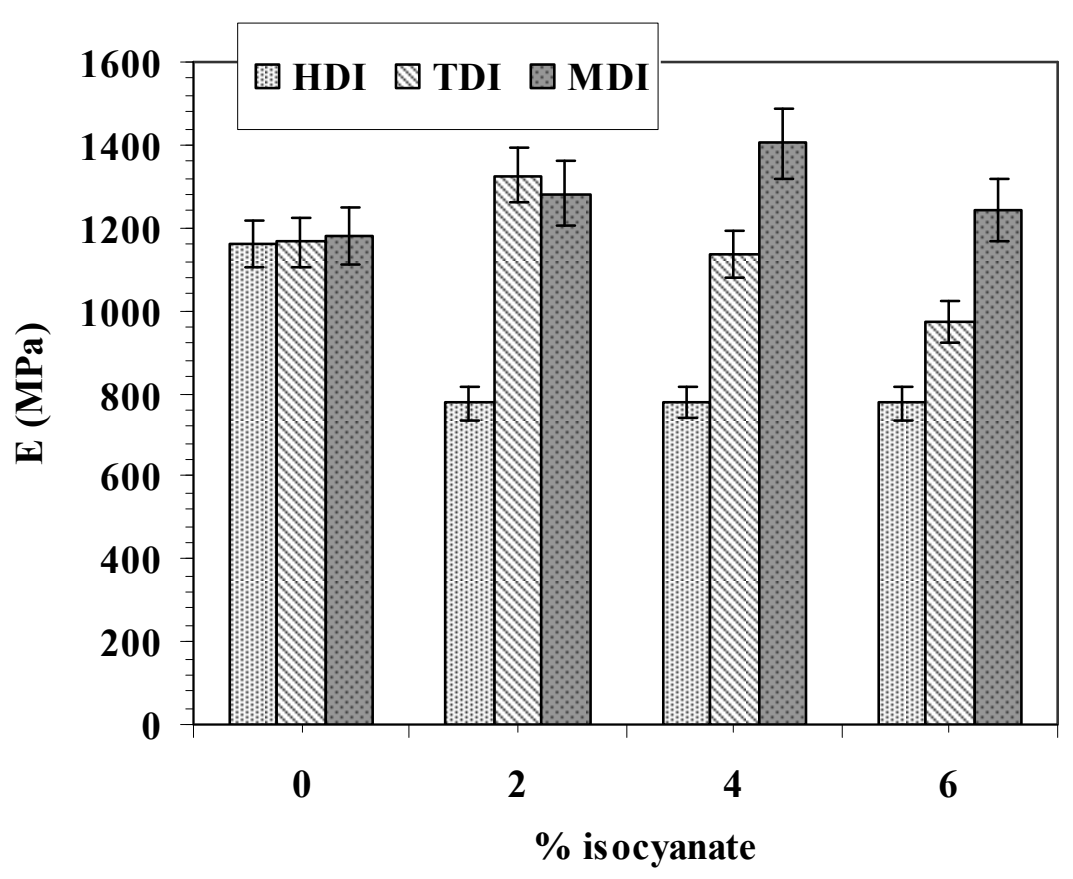

(a)

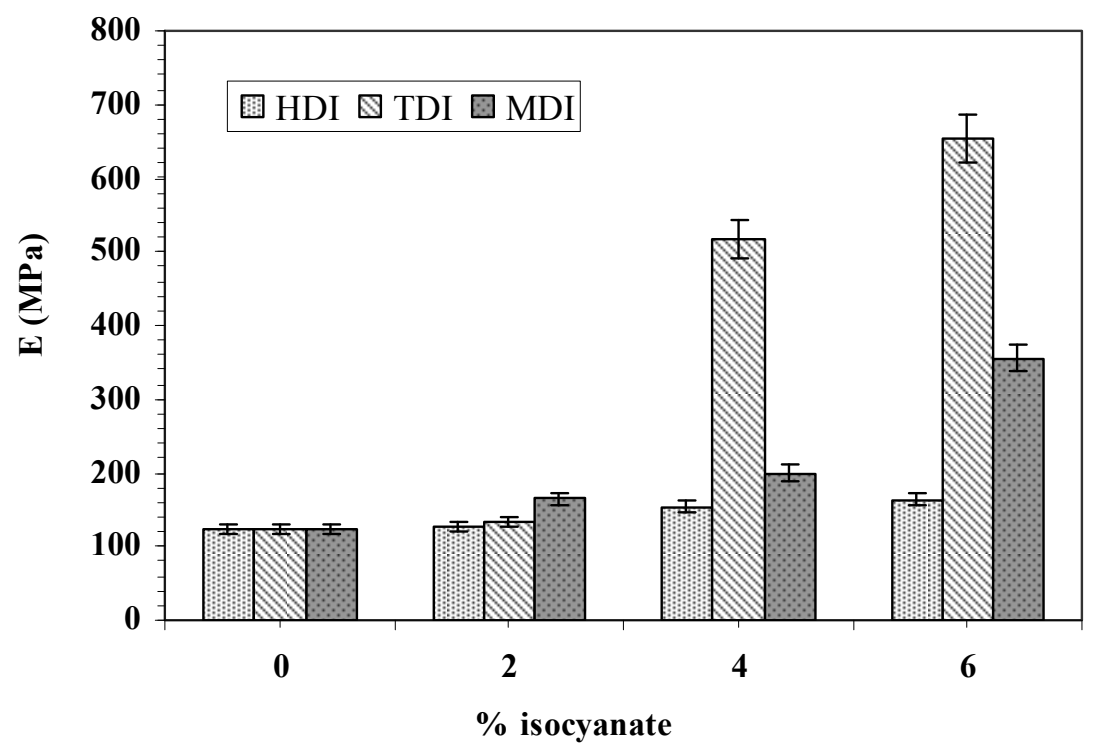

(b)

Fig. 7. Evolution of the tensile modulus for $\mathrm{ST}_{58} \mathrm{GLY}_{19}$ composition containing different amount of isocyanates (a) after two days ageing at $23^{\circ} \mathrm{C}$ and $50 \%$ relative humidity, and (b) after 40 days ageing 


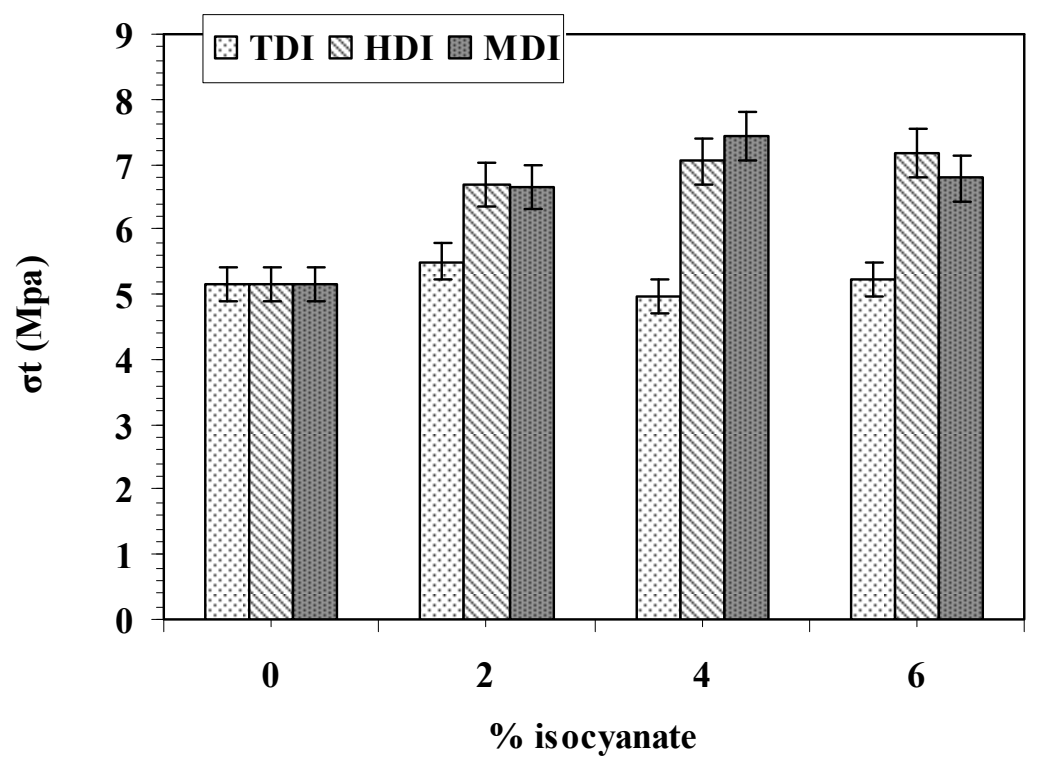

(a)

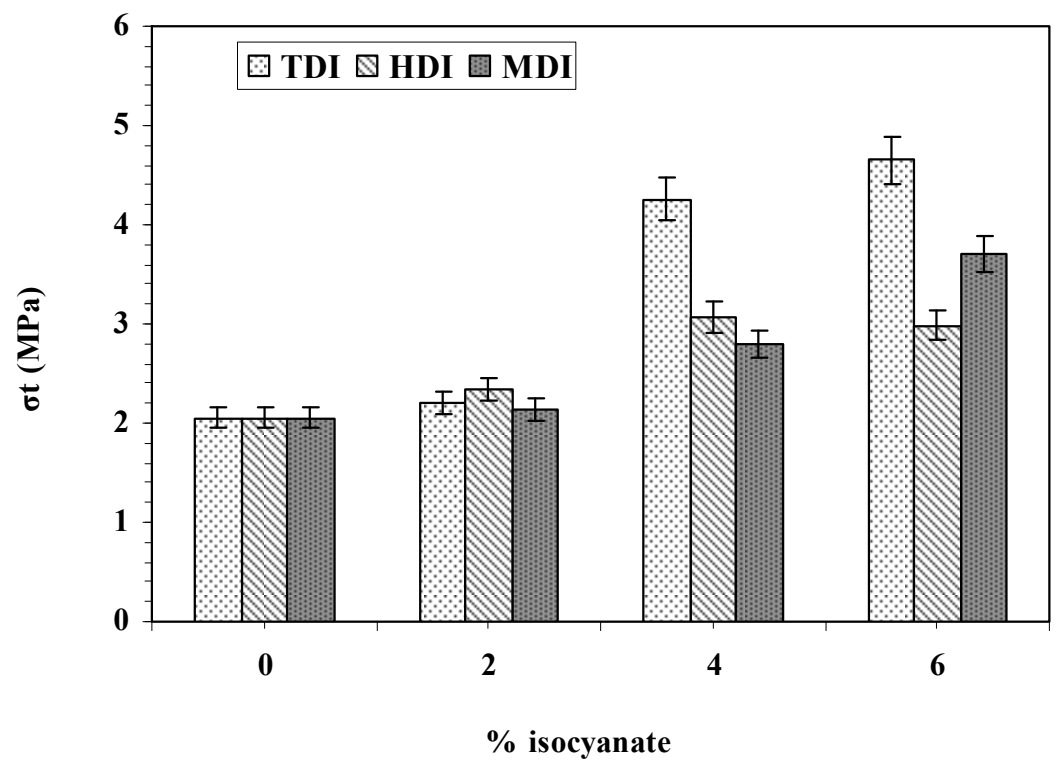

(b)

Fig. 8. Evolution of the tensile strength for $\mathrm{ST}_{58} \mathrm{GLY}_{19}$ composition containing different amount of isocyanates (a) after two days ageing at $23^{\circ} \mathrm{C}$ and $50 \%$ relative humidity, and (b) after 40 days ageing 


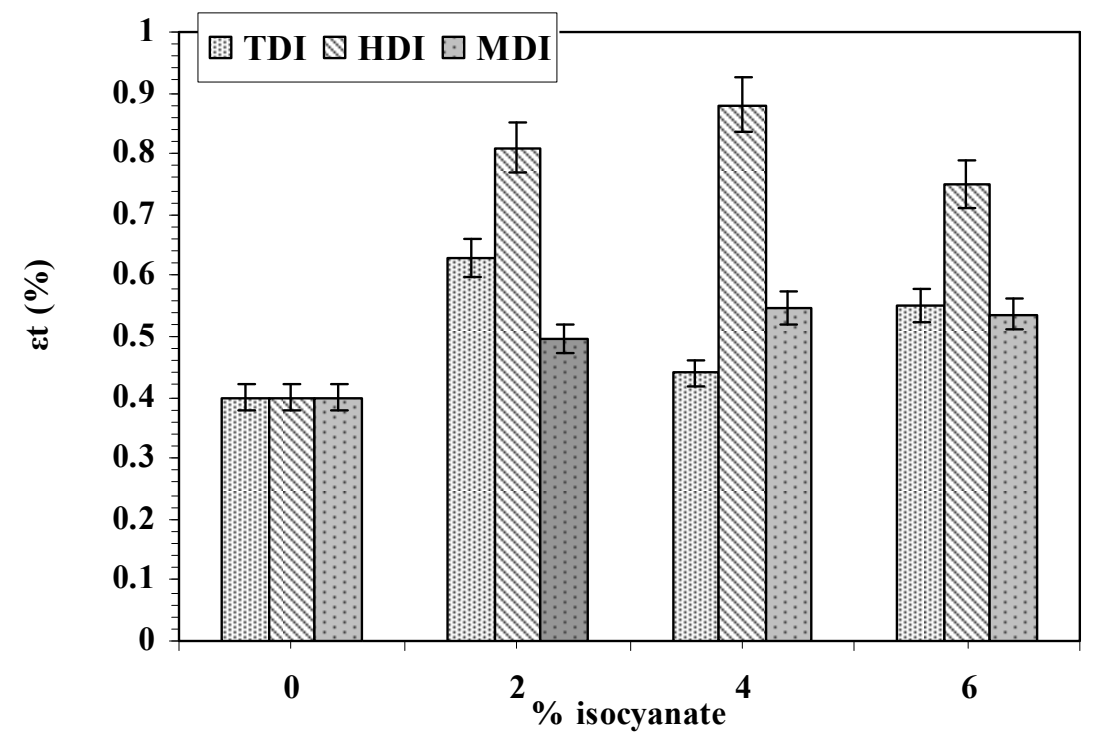

(a)

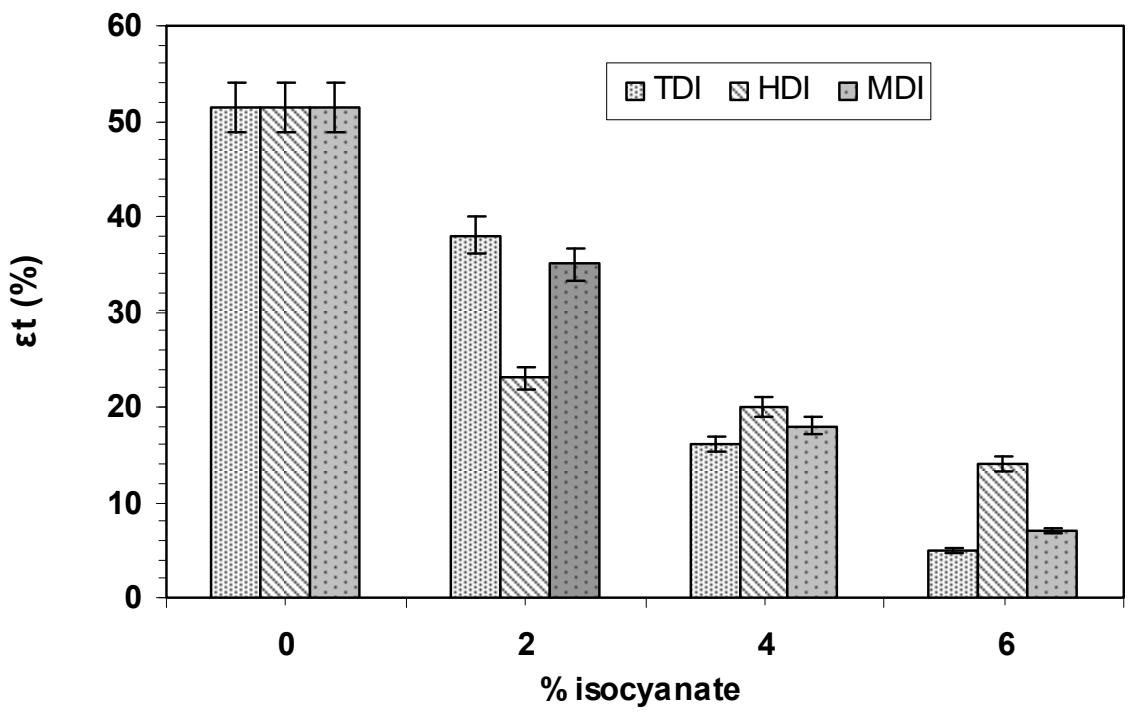

(b)

Fig. 9. Evolution of the strain for $\mathrm{ST}_{58} \mathrm{GLY}_{19}$ composition containing different amount of isocyanates (a) after two days ageing at $23^{\circ} \mathrm{C}$ and $50 \%$ relative humidity, and (b) after 40 days ageing

At $50 \% \mathrm{RH}$, the addition of isocyanate derivative moderately decreased the water uptake, as shown in Table 3. The higher the amount of isocyanate added, the more notable was the observed effect. At $6 \mathrm{wt} \%$ of MDI or TDI, the reduction in water uptake at equilibrium was about $20 \%$ with respect to starch-glycerol blend. However, at $70 \%$ $\mathrm{RH}$, independently of its content or structure, the addition of isocyanate did not bring about any evolution in the water uptake, despite the relatively hydrophobic character of the material involving 6\% MDI and TDI or 4\% HDI. Therefore, it seems that starch and 
glycerol content is the major factor affecting the water absorption of the ST/GLY blends. The introduction of a relatively low amount of hydrophobic compound linked to starch and plasticizer molecules is not enough to mask the hydroxyl group and impede water to diffuse inside the matrix, establishing hydrogen bonding between the available hydroxyl groups of starch and plasticizer. This fact explains the necessity of association of plasticized starch with a relatively high amount (between 30 and 50\%) of another biodegradable polymer, like polycaprolactone (PCL), poly(lactic acid) (PLA), or poly(hydroxybutyrate-Co-valerate) (PHBV), in order to overcome the extreme sensibility of TPS to moisture uptake and to obtain a useful starch-based biopolymer with stable behaviour.

Table 3. Evolution of the Crystallinity Index and Water Uptake of Formulations of Thermoplastic Starch Plasticized with Glycerol and MDI

\begin{tabular}{|l|c|c|c|}
\hline \multicolumn{1}{|c|}{ Formulation } & $\begin{array}{c}\text { T processing } \\
\left({ }^{\circ} \mathbf{C}\right)\end{array}$ & $\begin{array}{c}\text { Cristallinity } \\
\text { degree (\%) }\end{array}$ & MWU (\%) \\
\hline $\mathrm{ST}_{58} \mathrm{GLY}_{19} \mathrm{~W}_{23}$ & 120 & $11.2[0.5]$ & 7.6 \\
\hline $\mathrm{ST}_{58} \mathrm{GLY}_{19} \mathrm{~W}_{23}$ & 130 & $10.8[0.5]$ & 7.6 \\
\hline $\mathrm{ST}_{58} \mathrm{GLY}_{19} \mathrm{~W}_{23}$ & 140 & $11.1[0.5]$ & 7.6 \\
\hline $\mathrm{ST}_{58} \mathrm{GLY}_{24} \mathrm{~W}_{18}$ & 120 & $9.7[0.5]$ & 8.5 \\
\hline $\mathrm{ST}_{58} \mathrm{GLY}_{29} \mathrm{~W}_{13}$ & 120 & $9.4[0.5]$ & 9.5 \\
\hline $\mathrm{ST}_{58} \mathrm{GLY}_{19} \mathrm{~W}_{23}-2 \% \mathrm{MDI}$ & 140 & $11.0[0.5]$ & 6.7 \\
\hline $\mathrm{ST}_{58} \mathrm{GLY}_{19} \mathrm{~W}_{23}-4 \% \mathrm{MDI}$ & 120 & $10.8[0.5]$ & 6.4 \\
\hline $\mathrm{ST}_{58} \mathrm{GLY}_{19} \mathrm{~W}_{23}-6 \% \mathrm{MDI}$ & 120 & $10.8[0.5]$ & 5.8 \\
\hline $\mathrm{ST}_{58} \mathrm{GLY}_{24} \mathrm{~W}_{18}-2 \% \mathrm{MDI}$ & 120 & $9.8[0.5]$ & 7.6 \\
\hline $\mathrm{ST}_{58} \mathrm{GLY}_{24} \mathrm{~W}_{18}-4 \% \mathrm{MDI}$ & 120 & $10.2[0.5]$ & 6.8 \\
\hline
\end{tabular}

\section{Dynamic Mechanical Thermal Analysis (DMTA)}

DMTA analysis was also carried out to investigate the mechanical behaviour of materials and to obtain information about the relaxation mechanisms that may be correlated with the dynamics and the microstructure of the material. The evolution of the storage modulus $\left(E^{\prime}\right)$ and loss factor $(\tan \delta$ ) of TPS samples (Fig. 11) containing 19\% glycerol displayed a typical behaviour of a partially miscible system with two main transitions. The first relaxation at around $-55{ }^{\circ} \mathrm{C}$ is attributed to the relaxation of the phase rich in glycerol (Lafargue et al. 2007; de Menezes et al. 2007; Wilpiszewska and Spychaj 2007; da Róz et al. 2009). The second one (labelled $\alpha$ ), in the $40-50^{\circ} \mathrm{C}$ range, corresponds to the glass transition temperature $(\mathrm{Tg})$ of a plasticized starch phase (Forssel et al. 1997). It can be seen from Figs. 10 and 11 that in presence of isocyanates the drop in the storage modulus was more pronounced, namely with TDI. Further, in comparison to the composition $\mathrm{ST}_{58} \mathrm{GLY}_{19}$ showing a broad $\alpha$-relaxation, the addition of HDI, MDI, or TDI brought about an intensification of this relaxation, which became well resolved and less broad, even at low levels of isocyanates, e.g. $2 \mathrm{wt} \%$. This result may be indicative of a better degree of microstructure homogeneity of the glycerol-strarch phase, i.e. plasticized starch, as a result of the partial linking of glycerol with the amorphous part of 
starch chains. In fact, even if the amount of added isocyanates is much lower than glycerol or starch, this level may be enough to favour the linking of the plasticizer to starch chains if we take in to account that only a fraction of the added glycerol will be in solution within starch. The remaining part will segregate in a glycerol-rich phase. This later remained unchanged with isocyanate incorporation, as attested by the maintenance of the $\beta$ relaxation temperature and magnitude.

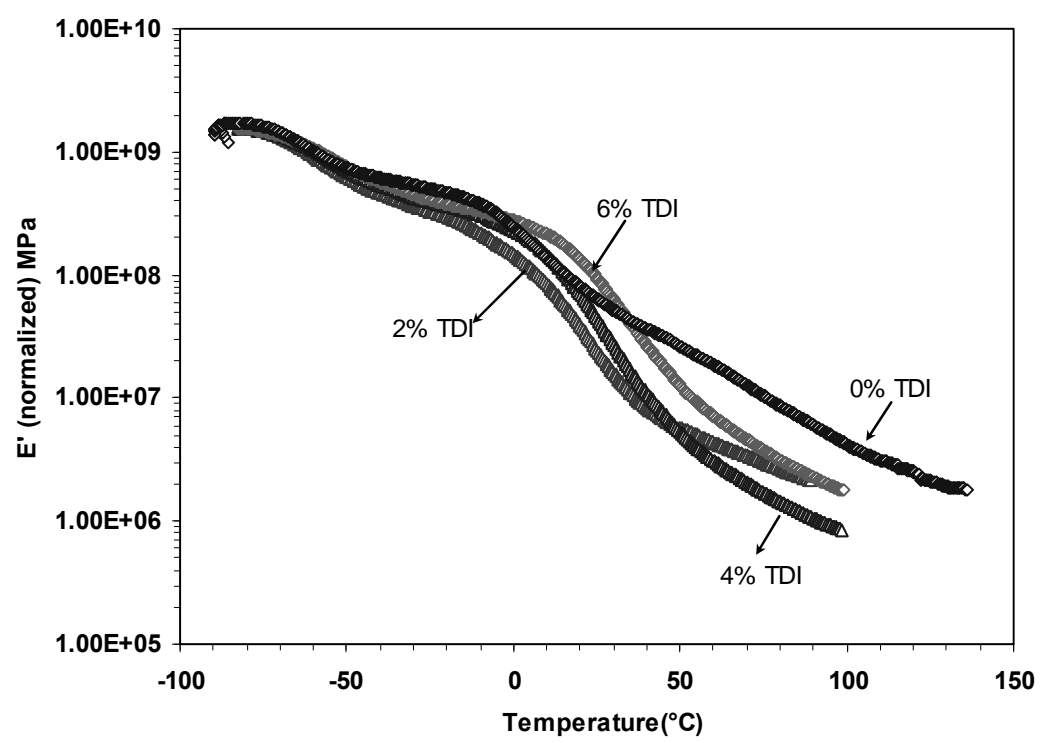

(a)

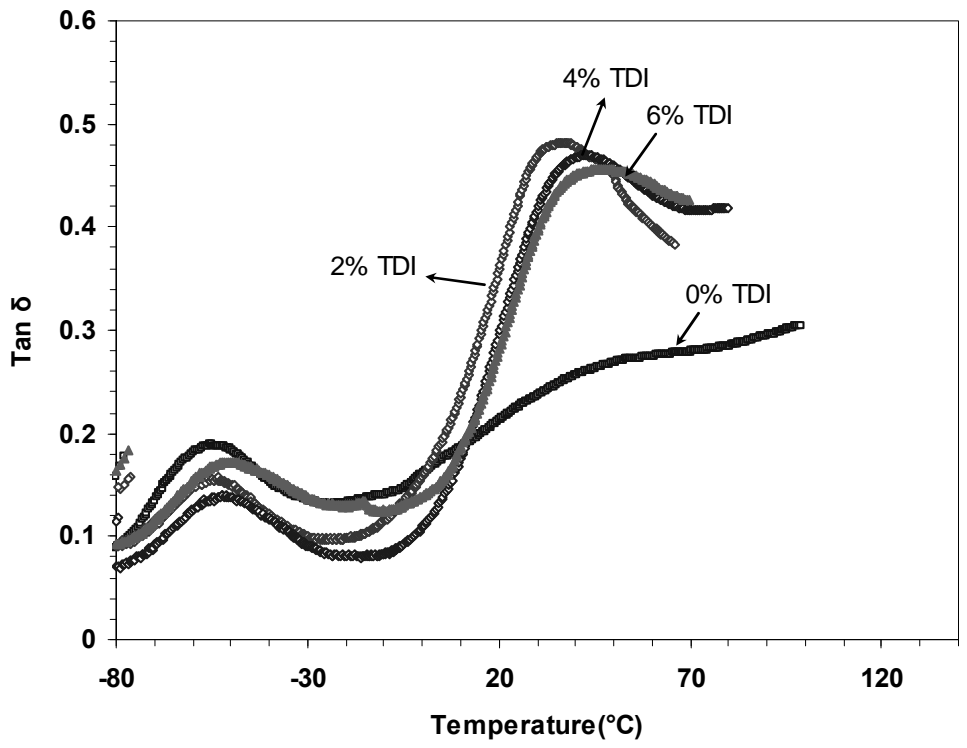

(b)

Fig. 10. Evolution (a) of the storage modulus, and (b) of the loss modulus versus temperature for $\mathrm{ST}_{58} \mathrm{GLY}_{19}, \mathrm{ST}_{58} \mathrm{GLY}_{19}$-TDI: Frequency measurements $1 \mathrm{~Hz}$. Scanning rate $2^{\circ} \mathrm{C} / \mathrm{min}$ 


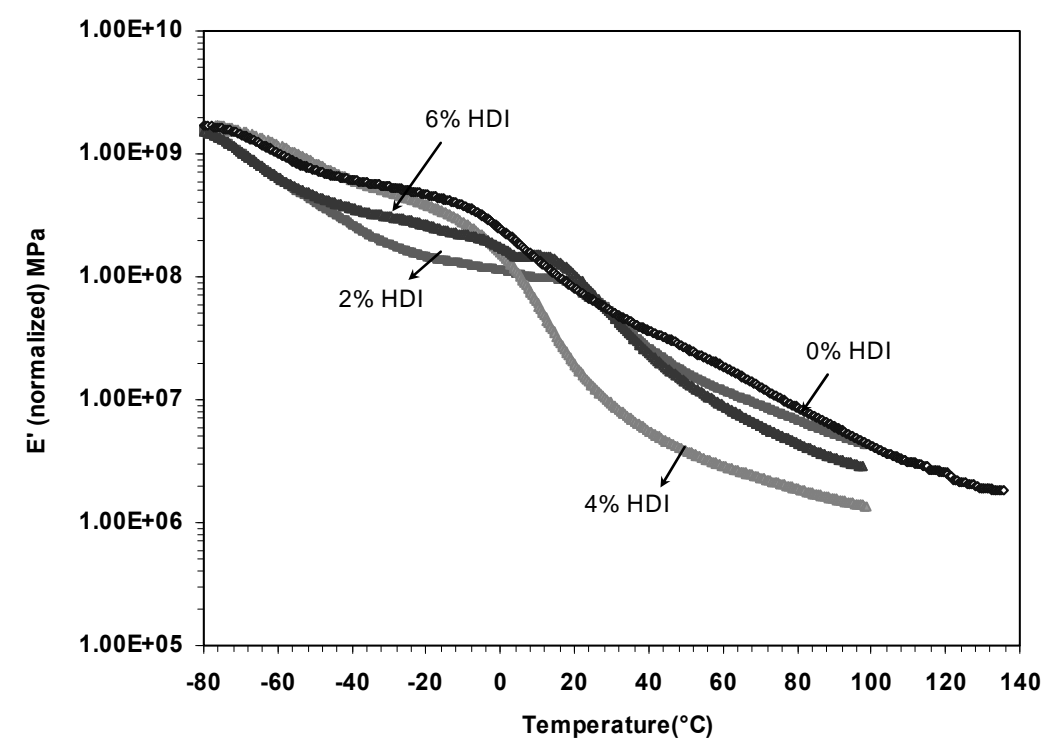

(a)

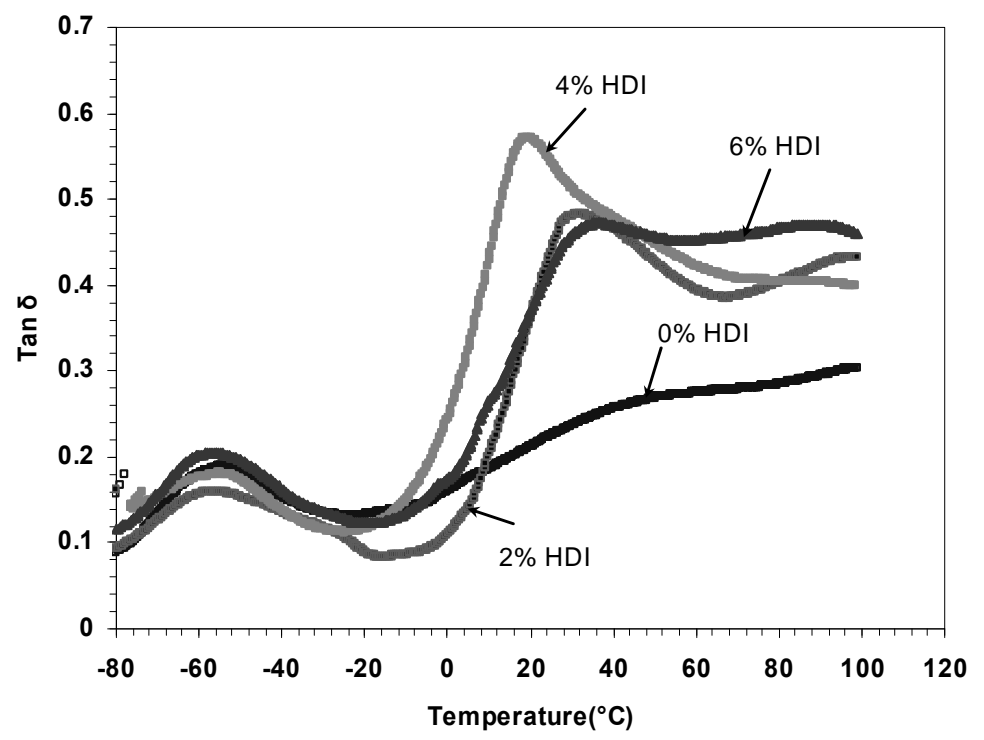

(b)

Fig. 11. Evolution (a) of the storage modulus, and (b) of the loss modulus versus temperature for $\mathrm{ST}_{58} \mathrm{GLY}_{19}, \mathrm{ST}_{58} \mathrm{GLY}_{19}-\mathrm{HDI}$ : Frequency measurements $1 \mathrm{~Hz}$. Scanning rate2 ${ }^{\circ} \mathrm{C} / \mathrm{min}$.

\section{CONCLUSIONS}

Thermoplastic starch was prepared using glycerol as plasticizer, and it was modified with different di-isocyanate derivatives. The material was prepared through in situ reactive modification of thermoplastic starch (TPS) followed by compressionmoulding. Increasing plasticizer level from 19 up to $29 \%$ and the addition of isocyanante 
up to $10 \%$ did not alter the Va-type crystallinity nor affect the crystallinity degree, which remained roughly constant at $10-11 \%$, within the measurement error.

The modulus and the tensile strength of the different TPS samples declined after 40 days of ageing, while the strain rose significantly, which was associated with the water uptake of the material that contributed to a boosting of the plasticizing effect. The mechanical evolution became less pronounced with the addition of aromatic isocyanates at a level exceeding 4 to $6 \mathrm{wt} \%$. Despite an enhancement in the hydrophobic character of the TPS after addition of iscocyanate above $4 \mathrm{wt} \%$, the water uptake of the material did not seem to be highly affected by the modification of isocyanates. At $6 \mathrm{wt} \%$ of MDI or TDI content, the reduction in water uptake, at the equilibrium, was about $20 \%$ with respect to starch-glycerol blend. The DMTA analysis revealed intensification of the $\alpha$ relaxation, which became well resolved and less broad after the addition of isocyanates, even at level below $2 \mathrm{wt} \%$.

\section{REFERENCES CITED}

Amass, W., Amass, A., and Tighe, B. (1998). “A review of biodegradable polymers: Uses, current developments in the synthesis and characterization of biodegradable polyesters, blends of biodegradable polymers and recent advances in biodegradation studies," Polym. Int. 47, 89-144.

Araújo, M. A., Cunha, A., and Mota, M. (2004). "Enzymatic degradation of starch-based thermoplastic compounds used in protheses: Identification of the degradation products in solution," Biomaterials 25, 2687-2693.

Avérous, L., Fringant, C., and Martin, O. (1999). "Coextrusion of biodegradable starchbased materials," In: Colonna, P., and Guilbert, S. (eds.), Biopolymerscience: Food and Non Food Applications, INRA editions, Jasberg BK, Paris, 207-212.

Avérous, L. (2004). "Biodegradable multiphase systems based on plasticized starch: A review," J. Macromol. Sci. Part-C 44, 231-274.

Belgacem, M. N., and Gandini, G. (2008). In: Monomers, Polymers and Composites from Renewable Resources, Elsevier, 321-340.

Carvalho, A. J. F., Curvelo, A. A. S., and Gandini, A. (2005). "Surface chemical modification of thermoplastic starch: Reactions with isocyanates, epoxy functions and stearoyl chloride," Indust. Crops Prod. 21, 331-336.

Da Róz, A. L., Curvelo, A. A. S., and Gandini, A. (2009). "Preparation and characterization of cross-linked starch polyurethanes," Carbohyd. Polym. 77, 526529.

Da Róz, A. L., Carvalho, A. J. F., Gandini, A., and Curvelo, A. A. S. (2006). "The effect of plasticizers on thermoplastic starch compositions obtained by melt processing," Carbohydr. Polym. 63, 417-424.

De Menezes, A. J., Pasquini, D., Curvelo, A. A. S., and Gandini, A. (2007). "Novel thermoplastic materials based on the outer-shell oxypropylation of corn starch granules," Biomacromolecules 8, 2047-2050. 
Forssel, P. M., Mikkila, J. M., Moates, G. K., and Parker, R. (1997). "Phase and glass transition behaviour of concentrated barley starch-glycerol-water mixtures, A model for thermoplastic starch," Carbohyd. Polym. 34, 275-282.

Forssell, P. M., Hulleman, S. H. D., Myllarinen, P. J., Moates, G. K., and Parker, R. (1999). "Ageing of rubbery thermoplastic barley and oat starches," Carbohyd. Polym. 39, 43-51.

Gaudin, S., Lourdin, D., Le Botlan, D., Ilari, J. L., and Colonna, P. (1999). "Plasticisation and mobility in starch-sorbitol films," J. Cereal Sci. 29, 273-284.

Gomez, M. H., and Aguilera, J. M. (1984). "Physicochemical model for extrusion of corn starch," J. Food Sci. 49, 40-49.

Griffin, G. J. L. (1994). "Starch polymer blends,” Polym. Degrad. Stabil. 45, 241-247.

Lafargue, D., Pontoire, B., Buléon, A., Doublier, J. L., and Lourdin, D. (2007). "Structure and mechanical properties of hydroxypropylated starch films," Biomacromolecules 8, 3950-3958.

Lourdin, D., Coignard, L., Bizot, H., and Colonna, P. (1997). "Influence of equilibrium relative humidity and plasticizer concentration on the water content and glass transition of starch materials," Polymer 38, 5401-5406.

Lu, D. R., Xiao, C. M., and Xu, S. J. (2009). "Starch-based completely biodegradable polymer materials," Express Polym. Lett. 36, 366-375.

Ortel, G. (1994). Polyurethane Handbook, $2^{\text {nd }}$ Ed., Hanser Publisher, Munich.

Pareta, R., and Edirisinghe, M. J. (2006). "A novel method for the preparation of starch films and coatings," Carbohyd. Polym. 63, 425-431.

Park, J. S., Yang, J. H., Kim, D. H., and Lee, D. H. (2004). "Degradability of expanded starch/PVA blends prepared using calcium carbonate as the expanding inhibitor," $J$. Appl. Polym. Sci. 93, 911-919.

Schwach, E., and Avérous, L. (2004). "Starch-based biodegradable blends: Morphology and interface properties," Polym. Int. 53, 2115-2124.

Shogren, R. L., Fanta, G. F., and Doane, W. M. (1993). "Development of starch-based plastics - A reexamination of selected polymer systems in historical-perspective," Starch/Stärke 45, 276-280.

Silva, G. G. D., Sobral, P. J. A., Carvalho, R. A., Bergo, P. V. A., Mendieta-Taboada, O., and Habitante, A. M. Q. B. (2008). "Biodegradable films based on blends of gelatin and poly (vinyl alcohol): Effect of PVA type or concentration on some physical properties of films," J. Polym. Environ.16(4), 276-285.

Smits, A. L. M., Kruiskampa, P. H., VanSoest, J. J. G., and Vliegenthart, J. F. G. (2003). "The influence of various small plasticisers and malto-oligosaccharides on the retrogradation of (partly) gelatinised starch," Carbohyd. Polym. 51, 417-424.

Talja, A. R., Helén, H., Roos, Y. H., and Jouppila, K. (2007). "Effect of various polyols and polyol contents on physical and mechanical properties of potato starch-based films," Carbohyd. Polym. 67, 288-295.

Teramoto, N., Motoyama, T., Yosomiya, R., and Shibata, M. (2003). "Synthesis, thermal properties, and biodegradability of propyl-etherified starch," Eur. Polym. J. 39, 255 261. 
VanSoest, J. J. G., and Knooren, N. (1997). "Influence of glycerol and water content on the structure and properties of extruded starch plastic sheets during aging," J. Appl. Polym. Sci. 64, 1411-1422.

VanSoest, J. J. G., de Wit, D., and Vliegenthart, F. G. (1996). "Mechanical properties of thermoplastic waxy maize starch,” J. Appl. Polm. Sci. 61, 1927-1937.

VanSoest, J. J. G., Tournoisa, H., de Wita, D., and Vliegenthart, J. F. G. (1995). "Shortrange structure in (partially) crystalline potato starch determined with attenuated total reflectance Fourier-transform IR spectroscopy," Carbohyd. Resear. 279, 201-214.

Wang, X. L., Yang, K. K., and Wang, Y. Z. (2003). "Properties of starch blends with biodegradable polymers," J. Macromol. Sci., Pol. R. C43, 385-409.

Wiedmann, W., and Strobel, E. (1991). "Compounding of thermoplastic starch with twinscrew extruders," Starch-Stärke 43, 138-145.

Wilpiszewska, K., and Spychaj, T. (2007). "Chemical modification of starch with hexamethylene diisocyanate derivatives," Carbohyd. Polym. 70, 334-340.

Wu, Q., Wu, Z., Tian, H., Zhang, Y., Cai, S. (2008). "Structure and properties of tough thermoplastic starch modified with polyurethane microparticles", Ind. Eng. Chem. Res. 47 (24), 9896-9902

Article submitted: July 30, 2010; Peer review completed: Oct. 10, 2010; Revised version received and accepted: November 16, 2010; Published: November 17, 2010. 